\title{
Acquired hemophilia A: A rare cause of gross hematuria
}

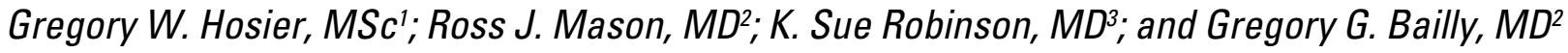

'Dalhousie Medicine; ${ }^{2}$ Department of Urology; 3 Department of Hematology, Dalhousie University, Halifax, NS, Canada

Cite as: Can Urol Assoc J 2015;9(11-12):E905-7. http://dx.doi.org/10.5489/cuai.3306 Published online December 14, 2015.

\section{Abstract}

Acquired hemophilia $\mathrm{A}$ is a rare condition caused by spontaneous development of factor VIII inhibitor. This condition most commonly presents with multiple hemorrhagic symptoms and isolated hematuria is exceedingly rare. Early diagnosis is important, as this condition carries a high mortality rate (13-22\%). We present a case of an 82-year-old man with isolated hematuria caused by a factor VIII inhibitor who was successfully treated with recombinant activated factor VII concentrate, as well as prednisone and cyclophosphamide.

\section{Case report}

An 82-year-old man presented to the emergency department with an eight-day history of painless gross hematuria. Past medical history included a left lung lobectomy for squamous cell carcinoma two months prior and radical prostatectomy with salvage radiation for prostate cancer 15 years prior. Most recent prostate-specific antigen (PSA) was $<0.04$ $\mathrm{ng} / \mathrm{mL}$. He was not taking any antithrombotic medications. Physical exam revealed moderate left flank pain, but was otherwise normal. Hemoglobin was $82 \mathrm{~g} / \mathrm{L}$, white blood cells $9 \times 10^{3} / \mathrm{L}$, platelets $278 \times 10^{9} / \mathrm{L}$, creatinine 158 , international normalized ratio (INR) 1 , partial thromboplastin time (PTT) $71 \mathrm{~s}$ (normal 26-38 s). Urinalysis showed $>900$ red blood cells per high-power field and 41 white blood cells per high-power field. The patient was treated empirically for a suspected urinary tract infection and referred to urology for cystoscopy.

Cystoscopy revealed significant active bleeding from the left ureteric orifice. An enhanced computed tomography (CT) revealed a $9.3 \mathrm{~cm}$ retroperitoneal hematoma in the right ileopsoas region and a $3.4 \mathrm{~cm}$ non-enhancing left lower pole renal lesion that was felt to be in keeping with a spontane- ous hemorrhage of a previously seen renal cyst, although a cystic mass could not be ruled out (Fig.1). There was no recurrent or metastatic disease seen.

The patient continued to have gross hematuria and developed subcutaneous hematomas of both forearms. A PTT correction study revealed the presence of a coagulation inhibitor, as the PTT only corrected to $42 \mathrm{~s}$. The Bethesda test confirmed an elevated level of factor VIII inhibitor at $6.16 \mathrm{IU} / \mathrm{mL}$ (normal $0.0 \mathrm{IU} / \mathrm{mL}$ ) and a low level of factor VIII at $0.02 \mathrm{IU} / \mathrm{mL}$ (normal $0.5-1.50 \mathrm{IU} / \mathrm{mL}$ ), confirming a diagnosis of acquired hemophilia A. No endoscopic investigations were performed on the advice of the hematology service, due to the risk of hemorrhage.

The patient was transferred to the hematology service and started on recombinant activated factor VII concentrate $\left(\mathrm{NiaStase}^{\circledR}\right)$ and oral prednisone $1 \mathrm{mg} / \mathrm{kg}$ daily. After seven days of treatment, his hemoglobin stabilized and his hematuria resolved. The NiaStase was discontinued. The patient was started on oral cyclophosphamide $100 \mathrm{mg}$ daily, along with continued prednisone. He was discharged five days later in good condition, with a PTT of $49 \mathrm{~s}$, factor VIII level of 0.09 $\mathrm{IU} / \mathrm{mL}$, factor VIII inhibitor level of 2.34 Bethesda Units $/ \mathrm{mL}$, and creatinine of $105 \mu \mathrm{mol} / \mathrm{L}$. Within two weeks, his factor VIII level was normal at $0.75 \mathrm{IU} / \mathrm{mL}$ and the factor VIII inhibitor level was undetectable. He was gradually weaned off cyclophosphamide and prednisone. Followup imaging ruled out the presence of a left lower pole renal mass.

\section{Discussion}

Gross painless hematuria is a common presenting symptom for many urological conditions. Hematological disorders are a rare cause of hematuria and typically present with hemorrhagic symptoms. Here, we present a case of acquired hemophilia A presenting as isolated hematuria in an 82-year-old male with a recent diagnosis of squamous cell lung carcinoma treated with lung resection. To the best of our knowledge, there are only seven previous cases reported of acquired hemophilia A presenting with isolated hematuria. ${ }^{1-6}$ 


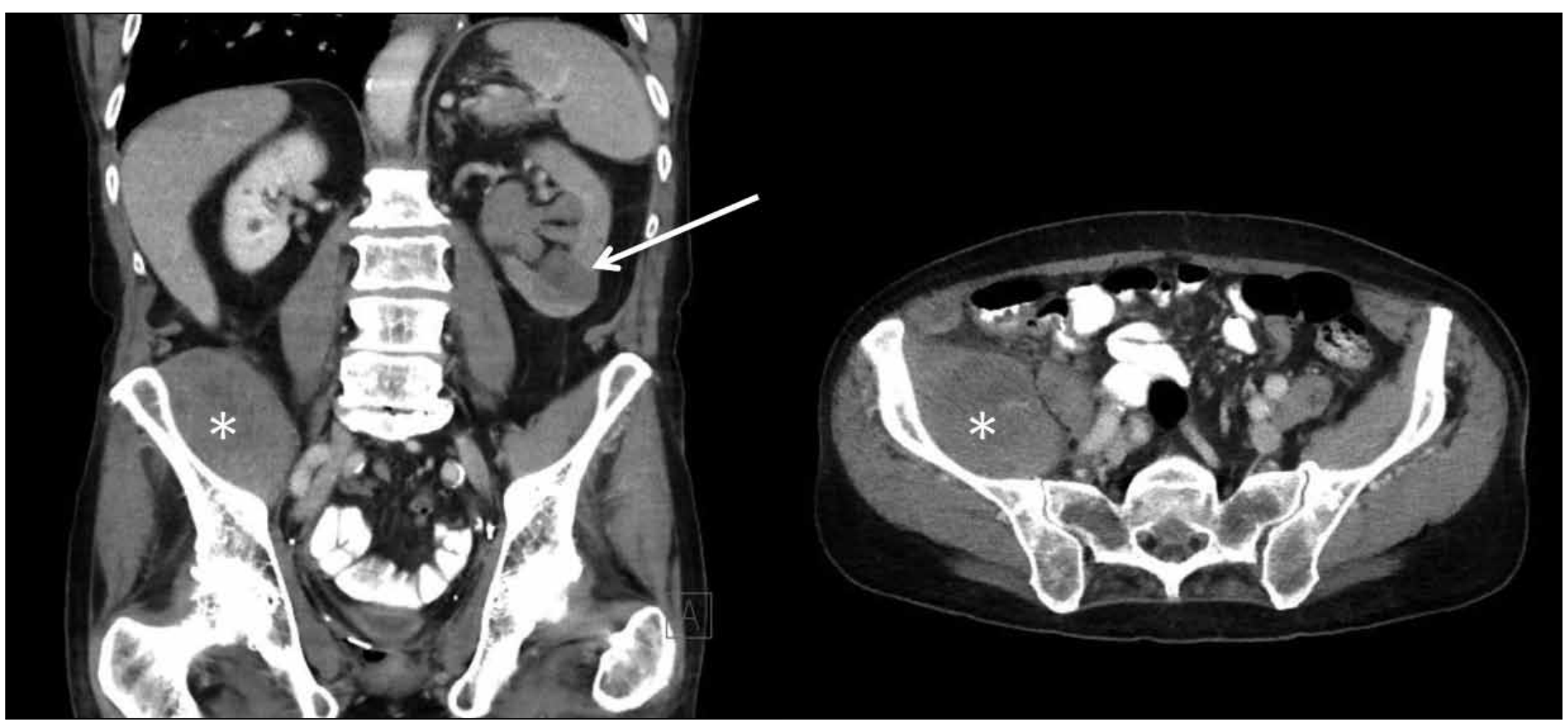

Fig.1. Enhanced abdominal CT showing $9.3 \mathrm{~cm}$ retroperitoneal hematoma $\left.{ }^{*}\right)$, a $3.4 \mathrm{~cm}$ non-enhancing left lower pole renal lesion (arrow), and left hydronephrosis.

Acquired hemophilia $\mathrm{A}$ is a rare condition with an incidence of about one case per million. ${ }^{1,2,7-9}$ Acquired hemophilia A typically presents with multiple hemorrhagic complications, including ecchymoses or hematomas (94\%), hematuria (30\%), compressive neuropathy $(24 \%)$, and hemarthrosis $(9 \%){ }^{2}$ Prolonged bleeding from intravenous (IV) sites and other iatrogenic sources is also common.

The disorder most commonly affects patients older than age 60 and affects men and women equally. ${ }^{1,2,7,9}$ It is fatal in $13-22 \%$ of patients, however, more recent studies have found the mortality rate to be closer to $4.5 \%$, which may reflect improved outcomes with treatment advances. ${ }^{9}$ The most common cause of death is retroperitoneal hemorrhage. $^{1-3}$ Underlying disorders are associated with the development of a factor VIII inhibitor in about half of cases, with the most common being autoimmune disorders (12\%), malignancy $(7-15 \%)$, pregnancy or post-partum $(10 \%)$, drug reactions (3-6\%), and dermatological disorders (2-5\%). ${ }^{1,2,7,9}$ Squamous cell lung cancer has been described in three cases prior to ours, however, no causal mechanism has been identified. ${ }^{10-12}$

Acquired hemophilia $A$ is caused by the spontaneous development of an auto-antibody directed against factor VIII that impairs its function in the coagulation pathway. ${ }^{13}$ The diagnosis is based on an isolated prolongation of PTT that is not corrected by a mixing study and confirmed by a reduced factor VIII level and a positive Bethesda assay. ${ }^{13}$

Treatment consists of maintaining hemostasis and eradicating the factor VIII inhibitor. First-line therapy for hemostasis is recombinant activated factor VII or activated prothrom- bin complex, which bypasses the factor VIII inhibitor in the coagulation cascade. ${ }^{13}$ If bypassing agents are not available or the inhibitor titer level is low ( $<5$ Bethesda units), factor VIII replacement can be used alone or in combination with desmopressin, which increases endogenous factor VIII levels. ${ }^{13}$ Typically bypassing agents are recommended since they are associated with significantly lower rates of bleeding compared to FVIII concentrates or desmopressin $(6.7 \%$ vs. $31.7 \%){ }^{14}$ To eradicate a factor VIII inhibitor, corticosteroids and immunosuppressant drugs, such as cyclophosphamide, azathioprine, vincristine, cyclosporine, and rituximab, are used alone or in combination. ${ }^{13,15}$

Although prospective randomized control studies are lacking, current evidence suggests that steroids and cyclophosphamide should be used as first-line agents. Steroids combined with cyclophosphamide result in more stable and complete remissions (70\%) compared to steroids alone $(48 \%)$ or rituximab-based regimens $(59 \%) .{ }^{13,15}$ Relapse was reported in $18 \%$ of patients treated with steroids and cyclophosphamide who achieved complete remission, indicating the need to follow patients closely after inhibitor eradication. ${ }^{13,15}$ Patients should be educated about the signs and symptoms of recurrence and urged to promptly report any bleeding or bruising

\section{Conclusion}

Acquired hemophilia $\mathrm{A}$ is a rare cause of gross hematuria, but should be considered in the presence of isolated prolongation of PTT. Rapid identification and treatment is needed, 
as the mortality of this condition is high. Instrumentation should be avoided in these patients unless absolutely necessary, to limit the risk of iatrogenic hemorrhagic complications.

Competing interests: Mr. Hosier and Dr. Mason declare no competing financial or personal interests. Dr. Bailly is or has been a member of Advisory Boards, on Speaker Bureaus, has received grants or honoraria from and has participated in clinical trials for Allergan, Astellas, and Pfizer. Dr. Robinson is or has been a member of Advisory Boards with Baxter, Bayer, Biogen-Idec, Celgene, CSL Behring, Janssen, Lundbeck, Novartis, Novo Nordisk, Pfizer, and Roche. He has also been on Speaker Bureaus for Roche and Janssen and has participated in clinical trials for Roche

This paper has been peer-reviewed.

\section{References}

1. Lottenberg R, Kentro TB, Kitchens CS. Acquired hemophilia: A natural history study of 16 patients with factor VIII inhibitors receiving little or no therapy. Arch Intern Med 1987;147:1077-81. http://dx.doi. org/10.1001/archinte.1987.00370060073014

2. Bossi $P$, Cabane J, Ninet J, et al. Acquired hemophilia due to factor VIII inhibitors in 34 patients. Am J Med 1998;105:400-8. http://dx.doi.org/10.1016/S0002-9343(98)00289-7

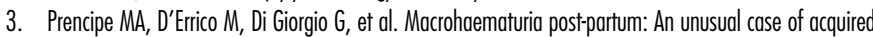
hemophilia after pregnancy. G Ital Nefrol 2002;19:204-8.

4. Shander A, Walsh C, Bailey H, et al. Acquired hemophilia presenting as profound hematuria: Evaluation, diagnosis, and management of elusive cause of bleeding in the emergency department setting. J Emerg Med 2013;45:el-6. http://dx.doi.org/10.1016/i.jemermed.2012.11.108
5. Kannan MS, Rai Kumar TR, Subramanian S. Acquired factor VIII inhibitor syndrome: A rare cause of hematuria. Indian J Urol 2015;31:73-4. http://dx.doi.org/10.4103/0970-1591.139551

6. Waltke EA, Jacobs SC, Hussey C V, et al. Massive hematuria due to acquired factor VIII inhibitor: Treatment with cyclophosphamide. Urology 1981;18:601-3. http://dx.doi.org/10.1016/00904295(81)90466-0

7. Green D, Lechner K. A survey of 215 non-hemophilic patients with inhibitors to Factor VIII. Thromb Haemost 1981; 45:200-3.

8. Collins PW, Hirsch S, Baglin TP, et al. Acquired hemophilia A in the United Kingdom: A two-year national surveillance study by the United Kingdom Hemophilia Centre Doctors' Organization. Blood 2007;109:1870-7. http://dx.doi.org/10.1182/blood-2006-06-029850

9. Knoebl P, Marco P, Baudo F, et al. Demographic and clinical data in acquired hemophilia A: results from the European Acquired Hemophilia Registry (EACH2). J Thromb Haemost 2012;10:622-31. http:// dx.doi.org/10.1111/i.1538-7836.2012.04654.x

10. Al-Ismail SA, Parry DH, Moisey CU, et al. Factor VIII inhibitor and bronchogenic carcinoma. Thromb Haemost 1979:41:291-5.

11. De Cataldo F, Baudo F, Redaelli R, et al. Acquired factor VIII:C inhibitor (lgG) and positive direct Coombs' test (lgM) in a patient with lung carcinoma: Clinical course and immunochemical studies. Scand J Haematol 1984;33:171-6. http://dx.doi.org/10.1111/i.1600-0609.1984.tb02392.x

12. Kondo H, Shigekiyo T, Koijma A, et al. Acquired factor VIII inhibitor in a patient with adenocarcinoma of the lung. Jpn I Clin Oncol 1992;22:49-53.

13. Janbain M, Leissinger CA, Kruse-Jarres R. Acquired hemophilia A: Emerging treatment options. J Blood Med 2015:6:143-50.

14. Baudo F, Collins $P$, Huth-Kühne $A$, et al. Management of bleeding in acquired hemophilia A: Results from the European Acquired Hemophilia (EACH2) Registry. Blood 2012;120:39-46. http://dx.doi. org/10.1182/blood-2012-02-408930

15. Collins $P$, Baudo $F$, Knoebl $P$, et al. Immunosuppression for acquired hemophilia A: Results from the European Acquired Hemophilia Registry (EACH2). Blood 2012;120:47-55. http://dx.doi.org/10.1182/ blood-2012-02-409185

Correspondence: Dr. Gregory W. Hosier, Dalhousie University, Halifax, NS, Canada gregory.hosier@ gmail.com 